\title{
Knowledge about Oral Health and Diseases in Public School Teachers of Lahore
}

${ }^{1}$ Salsbeel Khan, ${ }^{1}$ Amna Nauman Khan, ${ }^{1}$ Nauman Rauf Khan, ${ }^{2}$ Syed Amir Gilani, ${ }^{2}$ M. Athar Khan

Department of Community Dentistry, Sharif Medical \& Dental College, Lahore. University Institute of Public Health, University of Lahore

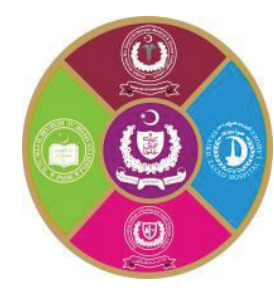

\begin{abstract}
Introduction: By imparting the awareness regarding the significance of oral hygiene, the repercussions of oral health problems can be avoided. Aims \& Objectives: The objectives of the study are to estimate the level of awareness of school teachers regarding oral health, dental and oral diseases. Place and duration of study: This study was conducted in Public schools of Lahore for a period of 9 months $\left(21^{\text {st }}\right.$ September, 2017 to $21^{\text {st }}$ June, 2018). Material \& Methods: It was a cross-sectional descriptive study in which currently enrolled teachers working in public schools were included. Convenience sampling technique was used. Data was collected by using semi-structured pretested questionnaire based on all the variables of the study. The data was entered and analyzed in SPSS version 24. Results: The overall mean age of 192 teachers was 27.12 \pm 7.84 years with $37 \%$ male and $63 \%$ females. In public school teachers, $4 \%$ had poor, $45.5 \%$ fair and $50.5 \%$ good knowledge regarding oral health and hygiene. $83 \%, 78.5 \%, 74 \%$ and $68.5 \%$ of the teachers were knowledgeable about bleeding gums, oral cancer, causes of bleeding gums and bad breath respectively. Qualification of teachers was strongly associated with assessing student's oral health and advising them not to have junk food with $\mathrm{p}$ value $<.001$. Female teachers were seen to be more significantly related with encouraging students in keeping good oral hygiene with $p$ value $<0.001$. Conclusion: Only $4 \%$ of school teachers had poor awareness about dental and oral health, whereas, majority of teachers had fair to good knowledge. Teachers can be motivated to mentor and guide the students about their oral health and maintenance of hygiene.
\end{abstract}

Key words: Knowledge, oral diseases, awareness, oral hygiene, oral health education, attitude, practices, qualification, primary school curriculum and school teachers.

\section{INTRODUCTION}

$\mathrm{T}_{\mathrm{c}}$ he term Oral health is vast and it means more than just healthy teeth as there are many other closely related anatomical structures which play important physiological roles and are related to different disorders like oral cancers, craniofacial disorders and birth defects, all of these factors constitute Oral Health. ${ }^{1}$ Oral health is directly related to person's general health as most diseases are as a result of progression of poor oral health. ${ }^{2}$ Common problems related to oral health are dental cavities, oral cancer and infectious diseases, lesions, injuries and gum diseases. ${ }^{3}$

Sixty to ninety percent of children and vast range of adults are affected by caries. ${ }^{4}$ The disease is more frequent in Asia and Latin American countries. ${ }^{5} \mathrm{~A}$ significant amount of the children's time is spent at school with their teachers. Children are at developing stage during their early schooling period and teachers can influence their hygiene and diet practices. ${ }^{6}$ When it comes to oral health awareness, causes of oral diseases and the ways of preventing them, the teachers can play a prime role in developing good habits and imparting awareness for the maintenance of good oral health amongst children. ${ }^{7,8}$

As teacher knowledge regarding importance of oral health is directly related to the educationing of the school children several studies have been conducted to assess the oral health status and awareness of the school teachers globally. ${ }^{9}$ Literature reveals information regarding some school-teacher's oral health knowledge and oral hygiene practices to be inadequate and poor. ${ }^{10,11}$ Hence, there is an urgent need for assessing teachers' knowledge, attitude and practices in Pakistani community followed by their training, motivation and promotion of oral health education through school based community outreach programs. 
Many studies are reporting the lack of implementation of oral health education within both public and private schools as one of the leading causes of decrease spread of oral health knowledge. ${ }^{12,13}$ Furthermore, with no academic support many students from both sectors also suffer awareness due to lack of facilitation from teachers and school administration. Public schools have not mentioned oral health education in their policy and this subject is neither taught nor practiced. ${ }^{14}$ Therefore, students' oral health practices and knowledge is poor. Teachers are willing to work for oral health education worldwide but there is no policy either at the government or private level to include oral health education in curriculum which can benefit the students and the community as a whole. Teachers feel comfortable in teaching oral health practices even within limited resources. ${ }^{15}$

The frequency of dental problems is higher among the school children with increased prevalence among the developing countries like Pakistan. ${ }^{16}$ With lack of dental educationing programs at the schools of Pakistan both public and private sector, the students are likely to suffer more from numerous dental and oral disease and hence expected to have a poor oral health. One way to fight this malicious problem is to educate the school teachers and encourage them to participate in oral health education programs; therefore, they are able to play their role by imparting awareness to their students. ${ }^{17}$ The objectives of the study are to estimate the level of knowledge of school teachers about oral health and dental problems, furthermore to improve school-teachers' own oral health knowledge and oral hygiene practices and also to create responsiveness to play their roles as mentors in promoting awareness among their students in public sectors regarding maintenance of good oral hygiene.

\section{MATERIAL AND METHODS}

It was a cross-sectional descriptive study in which currently enrolled teachers working in public schools were included. Convenience sampling technique was used. The duration of the study was 9 months i.e.; $21^{\text {st }}$ September, 2017 to $21^{\text {st }}$ June, 2018. The sample size was 192 which was derived from Cochran's formula (1977). ${ }^{18}$ Those teachers who had given their informed consent and had permanent jobs at schools were included in the study. Teachers not willing to participate or belonging to areas other than Lahore city were excluded. Data was collected by using semi-structured pretested questionnaire after approval from ethical committee of University Institute of Public Health and after obtaining informed consent from school teachers belonging to different areas of Lahore. Teachers were interviewed and information was filled in the questionnaire by the researcher. The responses in awareness of the teachers were graded as Good, Fair and Poor according to the following criteria:

\section{Oral Health Awareness}

Questions 1 to 20 are awareness based questions.

Total numbers assigned are 20 .

Number scored.... (0-7) $\longrightarrow$ Poor

Number scored.... (8-15) $\longrightarrow$ Fair

Number scored.... (16-20) $\longrightarrow$ Good

The questions asked regarding assessing Knowledge of public school teachers about different oral and dental conditions and their responses are given below in Table-1.

\begin{tabular}{|c|c|c|}
\hline \multicolumn{2}{|c|}{ Questions from Public School Teachers } & \multirow{2}{*}{$\begin{array}{l}\text { Percentage } \\
120(62.5 \%) \\
\end{array}$} \\
\hline \multirow{2}{*}{ Know about dental plaque } & Yes & \\
\hline & No & $72(37.5 \%)$ \\
\hline \multirow{2}{*}{ Know about calculus } & Yes & $17(8.5 \%)$ \\
\hline & No & $175(91.5 \%)$ \\
\hline \multirow{2}{*}{ Know about dental caries } & Yes & $74(38.5 \%)$ \\
\hline & No & $118(61.5 \%)$ \\
\hline \multirow{2}{*}{ Know about causes of dental caries } & Yes & $70(36.5 \%)$ \\
\hline & No & $122(63.5 \%)$ \\
\hline \multirow{2}{*}{ Know about fluoride prevents caries } & Yes & $7(4.0 \%)$ \\
\hline & No & $185(96.0 \%)$ \\
\hline \multirow{2}{*}{ Know about bleeding gums } & Yes & $160(83.0 \%)$ \\
\hline & No & $32(17.0 \%)$ \\
\hline \multirow{2}{*}{ Know about causes of bleeding gums } & Yes & $143(74.0 \%)$ \\
\hline & No & $49(26.0 \%)$ \\
\hline \multirow{2}{*}{ Know about bad breath } & Yes & $132(68.5 \%)$ \\
\hline & No & $60(31.5 \%)$ \\
\hline \multirow{2}{*}{ Know about causes of bad breath } & Yes & $76(39.5 \%)$ \\
\hline & No & $116(60.5 \%)$ \\
\hline \multirow{2}{*}{ Know about oral cancer } & Yes & $151(78.5 \%)$ \\
\hline & No & $41(21.5 \%)$ \\
\hline \multirow{2}{*}{ Know about causes of oral cancer } & Yes & $45(23.5 \%)$ \\
\hline & No & $147(76.5 \%)$ \\
\hline \multirow{2}{*}{ Know about methods of cleaning teeth } & Yes & $180(94.0 \%)$ \\
\hline & No & $12(6.0 \%)$ \\
\hline \multirow{2}{*}{$\begin{array}{l}\text { Know about the amount of paste to be } \\
\text { applied on tooth brush }\end{array}$} & Yes & $174(91.0 \%)$ \\
\hline & No & $18(9.0 \%)$ \\
\hline \multirow{3}{*}{ How often visit a dentist } & \begin{tabular}{|l|} 
Never \\
\end{tabular} & $156(81.0 \%)$ \\
\hline & Sometime & $22(11.5 \%)$ \\
\hline & On pain & $14(7.5 \%)$ \\
\hline \multirow{2}{*}{$\begin{array}{c}\text { Know about condition of your teeth } \\
\text { and gums }\end{array}$} & Yes & $162(84.5 \%)$ \\
\hline & No & $30(15.5 \%)$ \\
\hline \multirow{2}{*}{ Encourage students to brush regularly } & Yes & $109(57.0 \%)$ \\
\hline & No & $83(43.0 \%)$ \\
\hline \multirow{2}{*}{$\begin{array}{l}\text { Do you assess the oral health of your } \\
\text { students }\end{array}$} & Yes & $140(73 \%)$ \\
\hline & No & $52(27 \%)$ \\
\hline \multirow{2}{*}{$\begin{array}{l}\text { Know about lunch boxes should not } \\
\text { contain sticky/junk food }\end{array}$} & Yes & $163(85.0 \%)$ \\
\hline & No & $29(15.0 \%)$ \\
\hline \multirow{2}{*}{$\begin{array}{l}\text { Importance of including oral health } \\
\text { education in syllabus of primary } \\
\text { school }\end{array}$} & Yes & $172(89.5 \%)$ \\
\hline & No & $20(10.5 \%)$ \\
\hline \multirow{2}{*}{$\begin{array}{l}\text { Know about importance of getting } \\
\text { training in dental health education }\end{array}$} & Yes & $123(64.0 \%)$ \\
\hline & No & $69(36.0 \%)$ \\
\hline
\end{tabular}


Table-1: Knowledge about different oral and dental conditions among public school teachers.

\section{Statistical analysis:}

The data was entered and analyzed in SPSS version 24. $\mathrm{P}$-value $\leq 0.05$ was considered as significant.

\section{RESULTS}

A study was done on a total of 192 public school teachers from different public schools of Lahore, with a mean age of $27.12 \pm 7.84$ years. There were $72(37 \%)$ male and $120(63 \%)$ female. Qualification of these 192 public school teachers is given in the bar chart below in Figure-1.

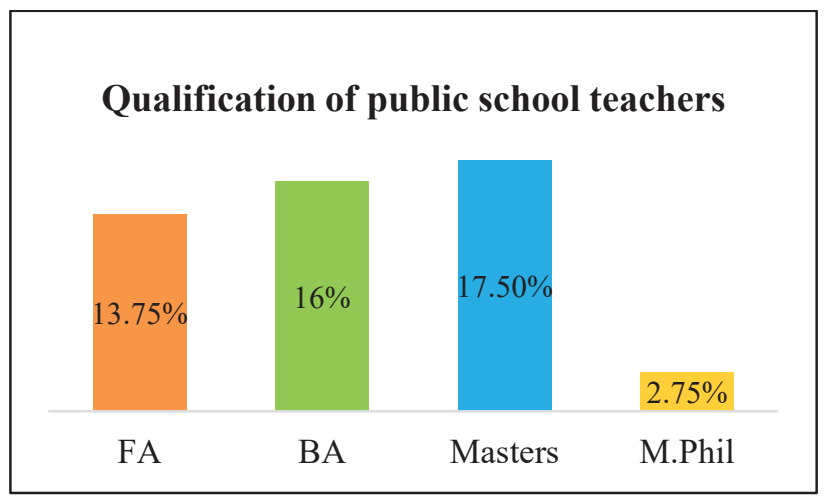

Fig-1: Qualification of public school teachers.

When assessed for the knowledge of different factors affecting the oral health for example caries, cause of caries, role of fluoridation, bleeding gums, bad breath, calculus, oral cancer and their causes, method of cleaning dentition, tooth paste usage, regular visit to dentist, etc., they were seen to be highly educated for bleeding gums, causes of bleeding gums, dental plaque and oral cancer. However, they were seen to be least knowledgeable for role of fluorides, calculus, causes of oral cancer and causes of dental caries as shown in Figure-2.

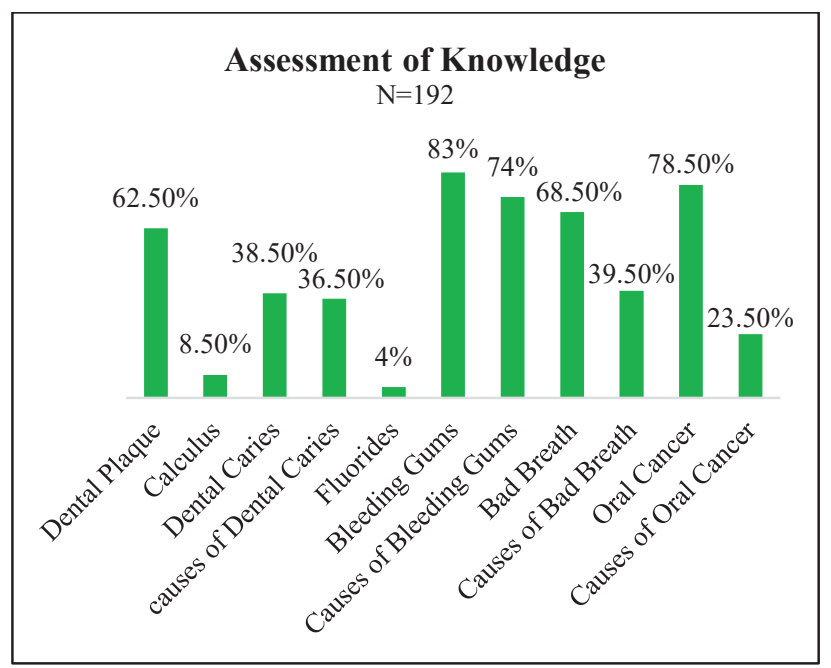

Fig-2: Knowledge assessment of the teachers regarding oral health

Overall, figure 3 below enlightens that there were only $4 \%$ teachers who had poor knowledge, whereas, $45.5 \%$ had fair and $50.5 \%$ had good knowledge regarding oral health and hygiene.

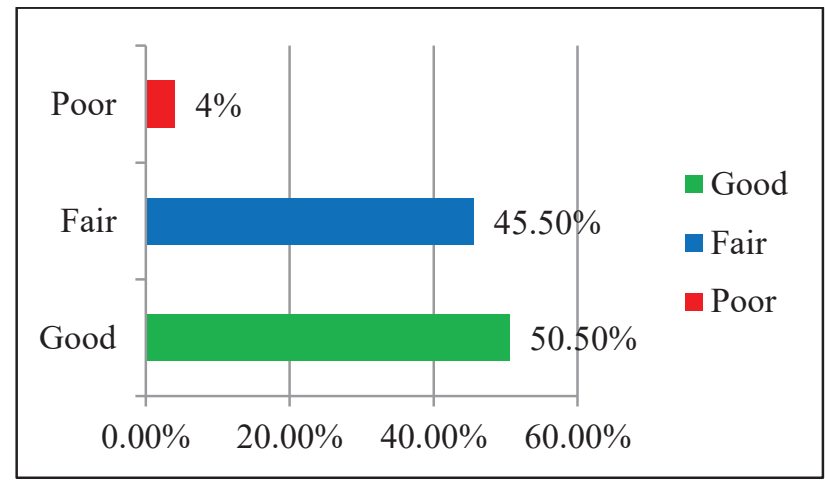

Fig-3: Comparison of knowledge among teachers

\section{DISCUSSION}

In this cross-sectional descriptive study done on teachers of public schools of Lahore a total of 192 teachers were taken of which $72(37 \%)$ were male and $120(63 \%)$ were female with a mean age of $27.12 \pm 7.84$ years. It was done using a structured questionnaire, designed and implemented on these teachers. All data obtained was entered into SPSS 24 and analyzed.

Variables related to oral hygiene practices were included within our questionnaire, factors linked to oral health diseases were also incorporated including dental caries, gingivitis and periodontitis. ${ }^{19}$ Frequency of cleaning, flossing, interdental brushes, wood sticks and gum picks were all considered for oral hygiene maintenance. ${ }^{20}$ Any initiative taken by the institute towards oral health education programming or building up already existent program was also taken in consideration of attitude and practices.

There is scarcity in literature in regards to such studies however a local study has been reported to assess the oral health knowledge and oral hygiene practices of public school teachers of Karachi, Sindh $2013 .^{21}$

This study reported $3 \%$ of teachers having knowledge of oral cancer which is way below that of our study which reports $78.5 \%$. This can be attributed to regional difference showing different sensitization to this devastating issue and also the study is five years old which can also play important role in difference in awareness. Another crosssectional survey was performed in Pondicherry India to determine knowledge, attitude and practice 
of school teachers towards oral health, inquiring about dental diseases, $47 \%$ of the respondents had knowledge about dental caries, 42\% knew about gum disease (plaque and calculus) while $83 \%$ acknowledged bleeding gums as a dental disease. ${ }^{6}$ These values are way less than reported in our study except knowledge of bleeding gums i.e., $83 \%$. This research reported knowledge of $77 \%$ in dental caries and $71 \%$ about gum disease (plaque and calculus) and the increase can be attributed to multiple factors like religion, socioeconomic status, education and regular dental visits. Also, predominantly the religion in Lahore is Islam which promotes cleaning five times a day, people are more aware of consequences of not cleaning properly and ending up into decay/caries, plaque, calculus and bleeding gums. Another study was conducted in India which reflected that $54 \%$ of the government school teachers were aware of the caries inhibiting properties of fluoride which is way more than seen in our study i.e., only $8 \%$. This shows lack of educationing among the Lahore teachers as they were unaware of role of fluoride in inhibiting caries due to lack of exposure from media or due to lack of dental health programs or education in the curriculum. There are also introduction to schemes for the improvement of health care of the public health in India which has increased awareness among the Indian public. ${ }^{22}$

In our study $50.5 \%$ had good, $45.5 \%$ had fair and $4 \%$ had poor knowledge regarding oral health and hygiene. Whereas, recently another study done in Nigeria in 2018 for the evaluation of oral health awareness in secondary school showed oral health knowledge of majority of the school teachers to be $16.67 \%$ with good, $58.33 \%$ with fair $25 \%$ of the teachers with poor oral health knowledge showing cohesion with this study group at only fair knowledge level. ${ }^{23}$ Their National Bureau of Statistics in 2010 stated that $60.9 \%$ of Nigerians are living in absolute poverty. ${ }^{24}$ In comparison our study group showed high proportion of public school teachers to have good knowledge of oral health which could be attributed to better socioeconomic status of Lahore city. ${ }^{24}$

\section{CONCLUSION}

Overall knowledge of the school teachers regarding oral health is good. However, knowledge about role of fluoride in prevention of caries is poor.

Oral Health education must be imparted to preschool and primary school teachers as a part of National Oral Health Care Program on a regular basis. Teachers should be motivated to mentor and guide the students about their oral health and maintenance of oral hygiene. Necessary changes in educational curriculum in schools should be done and further studies must be carried out in order to assess awareness levels after implementation of educational programs in both teachers and students.

\section{LIMITATIONS}

There were few limitations to our study. Firstly, there was a low response rate from the school teachers. This was due to lack of any educational curriculum design within the schools education system. Our second limitation was small sample size which also directly affected our first limitation in terms of better and accurate assessment of the response. With larger sample size and a longitudinal study design these limitations of low response rate and precision of result can be overcome.

\section{REFERENCES}

1. Hendricson WD, Cohen PA. Oral health care in the 21st century: implications for dental and medical education. Acad Med. 2001; 76(12):1181-206.

2. Griffin SO, Jones JA, Brunson D, Griffin PM, Bailey WD. Burden of oral disease among older adults and implications for public health priorities. Am JPublic Health. 2012; 102(3):411-18.

3. Salem LM. Multidisciplinary treatment craniofacial anomalies and its effects on children's oral cavity, psychology, and speech. 2016.

4. Iheozor-Ejiofor Z, Worthington HV, Walsh T, O'Malley L, Clarkson JE, Macey R, et al. Water fluoridation for the prevention of dental caries. Cochrane Database Syst Rev. 2015; 6(6).

5. Dixit LP, Shakya A, Shrestha M, Shrestha A. Dental caries prevalence, oral health knowledge and practice among indigenous Chepang school children of Nepal. BMC Oral Health. 2013; 13(1):20.

6. Sekhar V, Sivsankar P, Easwaran M, Subitha L, Bharath N, Rajeswary K, et al. Knowledge, attitude and practice of school teachers towards oral health in Pondicherry. J Clin Diagn Res. 2014; 8(8):ZC12.

7. Zhang X, Yang S, Liao Z, Xu L, Li C, Zeng H, et al. Prevalence and care index of early childhood caries in mainland China: evidence from epidemiological surveys during 19872013. Scientific Rep. 2016; 6.

8. Maganur PC, Satish V, Marwah N, Vishwas T, 
Dayan and M. Knowledge, Attitudes, and Practices of School Teachers toward Oral Health in Davangere, India. Int J Clin Pediatr Dent. 2017; 10(1):89.

9. Naidu GM, Prathap KR, Ram KC, Kiranmai G, Babburi S. Knowledge, attitude, and practices toward oral health among school teachers in" Guntur city," Andhra Pradesh, India. J Indian Assoc Public Health Dent. 2014; 12(3):226.

10. Mota A, Oswal KC, Sajnani DA, Sajnani AK. Oral health knowledge, attitude, and approaches of pre-primary and primary school teachers in Mumbai, India. Scientifica. 2016; 2016.

11. Maranhão MC, de Araújo LP, Vieira KA, Costa LS. Dental health knowledge and attitudes of primary school teachers toward dental health education in Maceio, Brazil. Pesqui Bras em Odontopediatria e Clínica Integrada. 2014; 14(2):115-28.

12. Jürgensen N, Petersen P. Promoting oral health of children through schools-Results from a WHO global survey 2012. Community Dent Health. 2013; 30(4):204-18.

13. Niranjan N, Knight S. An education intervention to improve oral health knowledge and behaviour in learners: A cluster randomized controlled trial. S Afr Dent J.2017;72(4):167-72

14. Kwan SY, Petersen PE, Pine CM, Borutta A. Health-promoting schools: an opportunity for oral health promotion. Bull World Health Organ. 2005; 83(9):677-85.

15. Sajjad S, Rehman MU, Roshan R. Knowledge, attitude and practices of primary school teachers regarding oral health in public and private schools of Rawalpindi. Pak Armed Forces Med J. 2016; 66(3):371-76.

16. Dawani N, Nisar N, Khan N, Syed S, Tanweer N. Prevalence and factors related to dental caries among pre-school children of Saddar town, Karachi, Pakistan: a cross-sectional study. BMC oral health. 2012; 12(1):59.

17. Chandrashekar BR, Suma S, Kiran K, Manjunath BC. The use of school teachers to promote oral hygiene in some secondary school students at Hyderabad, Andhra Pradesh, India: A short term prospective pilot study. J Family Community Med. 2012; 19(3):184.

18. Cochran WG. Sampling techniques-3. 1977.

19. Darby ML, Walsh M. Procedures Manual to Accompany Dental Hygiene-E-Book: Elsevier Health Sciences; 2009.

20. Claydon NC. Current concepts in tooth brushing and interdental cleaning. J Periodontol 2000 . 2008; 48(1):10-22.

21. Dawani N, Afaq A, Bilal S. Oral health knowledge, attitude and practices amongst teachers of public school set-up of Karachi. Pak J Dow Uni Health Sci. 2013; 7(1):15-19.

22. Shodan M, Prasad KV, Javali SB. School teachers' knowledge of oral disease prevention: a survey from Dharwad, India. Journal of investigative and clinical dentistry. 2012; $3(1): 62-67$.

23. Augustine EI, Afolabi O. Evaluation of oral health awareness of secondary school teachers. Adv Hum Biol. 2018; 8(1):31.

24. Anger B. Poverty eradication, millennium development goals and sustainable development in Nigeria. Journal of sustainable development. 2010; 3(4):138.

\section{The Authors:}

Dr. Salsbeel Khan

Demonstrator,

Community Dentistry,

Sharif Medical \& Dental College, Lahore.

Dr. Amna Nauman Khan

Associate Professor,

Community Dentistry,

Sharif Medical \& Dental College, Lahore.

Dr. Nauman Rauf Khan

Associate Professor,

Oral Pathology,

Sharif Medical \& Dental College, Lahore.

Prof. Dr. Syed Amir Gilani

University Institute of Public Health,

The University of Lahore.

Prof. Dr. M. Athar Khan

University Institute of Public Health,

The University of Lahore.

\section{Corresponding Author:}

Dr. Nauman Rauf Khan

Associate Professor,

Oral Pathology,

Sharif Medical \& Dental College, Lahore.

Email: dr.nrkhan@gmail.com 